\title{
Verubulin Hydrochloride
}

National Cancer Institute

\section{Source}

National Cancer Institute. Verubulin Hydrochloride. NCI Thesaurus. Code C64782.

The hydrochloride salt form of verubulin, a quinazoline derivative with potential dual antineoplastic activities. Verubulin binds to and inhibits tubulin polymerization and interrupts microtubule formation, resulting in disruption of mitotic spindle assembly, cell cycle arrest in the G2/M phase, and cell death. This agent is not a substrate for several subtypes of multidrug resistance $A B C$ transporters, such as P-glycoprotein, multidrug resistance-associated protein 1 (MRP1), and breast cancer resistance protein 1 (BCRP1); therefore, it may be useful for treating multidrug resistant (MDR) tumors that express these transporters. In addition, as a vascular disrupting agent (VDA), verubulin appears to disrupt tumor microvasculature specifically, which may result in acute ischemia and massive tumor cell death. 